\title{
In Memoriam: Roman M. Baevsky (1928-2020), a life in autonomic space medicine
}

\author{
Jens Tank $^{1,3} \cdot$ Jens Jordan ${ }^{1} \cdot$ Irina Funtova $^{2} \cdot$ Elena Luchitskaya $^{2} \cdot$ Oleg Orlov $^{2}$
}

๑) Springer-Verlag GmbH Germany, part of Springer Nature 2020

Roman M. Baevsky, a dedicated scientist, compassionate physician, beloved mentor, and dear friend left us on May 31, 2020 at the age of 91 years. He had served as chief researcher at the scientific center of the Russian Federation-Institute of Biomedical Problems of the Russian Academy of Sciences (IBMP). Throughout his career, his work was focused on autonomic cardiovascular control mechanisms and how they are challenged in extreme environments, particularly during space travel. Moreover, he developed the concept that non-invasive cardiovascular autonomic testing could identify individuals at increased risk before symptoms occurred to guide preventive measures.

Roman M. Baevsky began his scientific career as a military flight surgeon on Sakhalin Island from 1952 to 1957 and never stopped until the end of his remarkable life. His experience in aviation medicine provided a solid foundation for his pioneering work in space medicine. He was a physician scientist with exquisite engineering skills and profound physiological knowledge. Roman M. Baevsky was among the last Ph.D. students of Parin V.V., the legendary Russian founder of biocybernetics. Furthermore, he was co-founder of space cardiology in Russia [9]. He contributed substantially to the field over more than 5 decades always seeking to integrate space medicine with clinical applications on Earth (Fig. 1).

Roman M. Baevsky invented and developed the first Russian ballistocardiography devices, which picked up forces generated by the beating heart through sensors on the body surface. The methodology, which required that pilots placed their legs on the ballistocardiograph, provided

Jens Tank

jens.tank@dlr.de

1 Institute for Aerospace Medicine, German Aerospace Center (DLR), Linder Hoehe, 51147 Cologne, Germany

2 Institute of Biomedical Problems of RAS, Moscow, Russia

3 Aerospace Medicine, University of Cologne, Cologne, Germany cardiovascular function data within seconds at a time when echocardiography was not available [1]. He recognized that these tools could also have utility in larger scale epidemiological studies. Later on, he combined different non-invasive cardiovascular monitoring techniques including ballistocardiography in small wearable devices for applications in space [4]. Interestingly, ballistocardiography provides particularly valid information on cardiac forces while floating in weightlessness. Over the years, he conducted multiple experiments in space with continuously improved technology that is still used onboard the International Space Station $[5,7]$.

He was directly involved in preparation and medical support of the first animal and human space flights. For example, he obtained heart rate recordings in Leika, the first dog that flew safely to space. He also conducted such measurements in Yuri Gagarin, the first human being in space. Over the decades, he served as principal investigator for numerous space experiments onboard Soviet [2, 3] and Russian space vessels [6] and later on the International Space Stations (ISS) [11]. In addition, he was principal investigator in terrestrial space analog studies, such as dry immersion, isolation, and head-down tilt bedrest [10], in cooperation with many international partners.

One of his major aims was to have people on Earth benefit from scientific insight and technologies generated in space medicine. For example, back in the 60 s and 70 s of the last century, he established statistical and spectral analysis of the cardiac rhythm later called heart rate variability analysis to study the autonomic nervous system in space and on Earth [8]. He developed the concept that the transition process from health to disease should be captured, which he called "pre-nosological diagnosis". He wrote several books in Russian detailing the concept, which had an important impact on preventive-, sports-, and rehabilitation medicine in the country and affected public health policies of the Russian Ministry of Health [12]. 

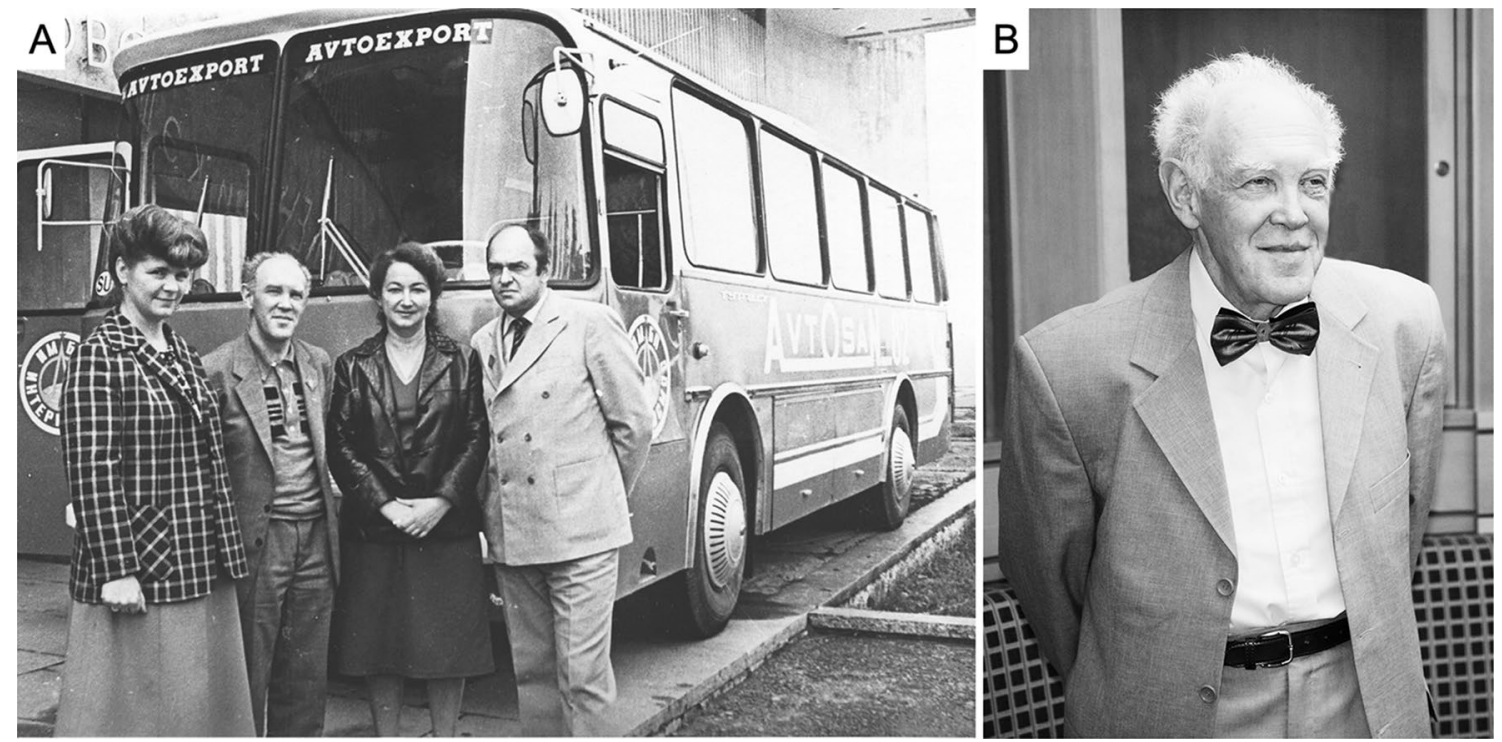

Fig. 1 a Roman Markovich Baevsky together with his research team (from left to right: Berseneva A.P., Baevsky R.M., Funtova I.I., Stepanov V.A.) in front of a mobile diagnostic laboratory developed in the early eighties (Autosan 82) at the Institute of Biomedical Prob- lems and equipped with space technology for cardiovascular monitoring including telemetric data transfer and analysis for field studies and diagnostics in rural areas. b Roman Markovich Baevsky during his 80th birthday in 2008
Roman M. Baevsky authored numerous scientific papers in domestic and international journals and twelve inventions. For many years, he mentored younger scientists in different stages of their career including one of the coauthors (JT) who prepared his master thesis in the Baevsky lab in the mid-80s and continued to collaborate ever since. Roman M. Baevsky had a sparkling in his eyes when explaining why integrated physiology research is crucial in space medicine and in the clinic alike. His fascination for the autonomic nervous system attracted generations of scientists to the field.

Roman Baevsky will be remembered as an extraordinarily hardworking scientist, demanding on himself, devoted to science, but at the same time as a wise, friendly, modest, and kind person. Particularly impressive was his open mind to other research areas and his willingness to cooperate and to share ideas. His colleagues, students, and many scientists and friends will always keep a good memory of Roman Baevsky, a wonderful human being.

\section{Funding None.}

\section{Compliance with ethical standards}

Conflict of interest None.

\section{References}

1. Baevskii RM (1958) Possibility of the utilization of a ballistocardiographic method in medical examination in aviation. Voen Med Zh 86:48-51

2. Baevskiǔ RM, Funtova II (1982) Ballistocardiographic studies during the 4th expedition on the Saliut-6 orbital station. Kosmicheskaia biologiia i aviakosmicheskaia meditsina 16:34-37

3. Baevskii RM, Volkov YN (1965) Clinicophysiological evaluation of seismocardiographic data obtained during space flights of Vostok V and Vostok VI Federation proceedings. Transl Suppl 24:953-956

4. Baevsky RM (1997) Noninvasive methods in space cardiology. J Cardiovasc Diagn Proced 14:161-171

5. Baevsky RM, Baranov VM, Funtova II, Diedrich A, Pashenko AV, Chernikova AG, Drescher J, Jordan J, Tank J (2007) Autonomic cardiovascular and respiratory control during prolonged spaceflights aboard the International Space Station. J Appl Physiol 103:156-161

6. Baevsky RM, Moser M, Nikulina GA, Polyakov VV, Funtova II, Chernikova AG (1998) Autonomic regulation of circulation and cardiac contractility during a 14-month space flight. Acta Astronaut 42:159-173

7. Delière Q, Migeotte PF, Neyt X, Funtova I, Baevsky RM, Tank J, Pattyn N (2013) Cardiovascular changes in parabolic flights assessed by ballistocardiography. In: Conference proceedings, annual conference IEEE engineering in medicine and biology society, pp 3801-3804

8. Goldberger AL, Bungo MW, Baevsky RM, Bennett BS, Rigney DR, Mietus JE, Nikulina GA, Charles JB (1994) Heart rate 
dynamics during long-term space flight: report on Mir cosmonauts. Am Heart J 128:202-204

9. Parin VV, Baevsky RM, Gazenko OG (1965) Heart and circulation under space conditions. Cor et vasa 7:165-184

10. Shiraishi M, Kamo T, Nemoto S, Narita M, Kamegai M, Baevsky RM, Funtova II (2003) Blood pressure variability during 120-day head-down bed rest in humans. Biomed Pharmacother 57(Suppl 1):35-38
11. Tank J, Baevsky RM, Funtova II, Diedrich A, Slepchenkova IN, Jordan J (2011) Orthostatic heart rate responses after prolonged space flights. Clin Auton Res 21:121-124

12. Ushakov IB, Orlov OI, Baevskiŭ RM, Bersen'ev E, Chernikova AG (2013) Conception of health: space-earth. Fiziol Cheloveka 39:5-9 